\title{
A Genre-based Study of Insurance Sales Agent-Client Interactions in Transformational China's Rural Areas
}

\author{
Weichao Wang ${ }^{1}$ \\ ${ }^{1}$ School of English for International Business, Guangdong University of Foreign Studies, Guangzhou, China \\ Correspondence: Weichao Wang, School of English for International Business, Guangdong University of Foreign \\ Studies, Guangzhou, China. E-mail: jasonwangw@163.com
}

Received: April 12, 2016 Accepted: April 28, 2016 Online Published: May 25, 2016

doi:10.5539/ijel.v6n3p88 URL: http://dx.doi.org/10.5539/ijel.v6n3p88

\begin{abstract}
Based on 10 authentic audio-recorded data, the study aims to explore the dynamics of the insurance sales agent-client interactions in transformational China's rural areas from a socio-cultural perspective. It sets out from generalizing the specific discursive patterns from moves and steps (Askehave \& Swales, 2001; Bhatia, 2005) of the utterances made in the agent-client interactions, governed by communicative purposes. For the first move, warming up, it deserves more attention as it serves crucial functions in the interactions. The paper delineates the different types and functions of warming up, and relates them to the underlying operating mechanism of rural agent-client interactions; another vital move, establishing credentials and trust, has also been analyzed in details, since trust is the pillar stone in the conclusion of insurance sales. Through the analysis, we hope to depict the transforming nature of the modern Chinese rural society, where old and traditional value system has been, for a large part, demolished, while new value system is yet to be established.
\end{abstract}

Keywords: rural China, transformation, insurance sales, move, trust

\section{Introduction}

This paper analyzes the dialogues between insurance sales agents and their clients from the perspective of genre analysis. More specifically, it studies the communicative purposes, moves and steps (Swales, 1991; Bhatia, 2005) of the insurance sales interactions in transformational rural China. The purpose is to uncover the dynamics of agent-prospect interaction in transformational rural China, represented by several villages in central China.

Insurance is a core institution of a society increasingly organized around managing risks. As Beck (1992) argues, risk society is also an individual society. The utilization of insurance sales agents' identity to achieve economic goals interact with key contemporary social tendencies: the responsibilization of the individual consumer, the erosion of the social safety net, fragmentation, individualism and the attenuation of family ties, the growth of a "flexible" labor force, and the downloading of regulatory responsibility from the government. Until recently, the hidden world of insurance has received surprisingly little attention from social scientists (Strange, 1996, p. 122; Baker \& Simon, 2013). Most academic research on insurance has been done by economists and researchers in business and finance. Nonetheless, insurance studies have recently emerged as a blossoming field for other researchers, especially in sociology, socio-legal studies and criminology (Baker \& Simon, 2013; Ericson \& Doyle, 2003; Ericson et al., 2003; Ericson \& Doyle, 2004a; 2004b; 2004c). In China, research on insurance are mostly done from economic, business and financial perspective, their primary interest is to investigate the current situations in China's insurance industry and offer certain suggestions to improve the efficiency and profitability of the insurance institutions from political, economic and marketing perspectives (Sheng, 2009; Zhu, 2009; Hu \& Wang, 2009; Shu \& Li, 2006; Yuan, 2008; Guo, 2009; Li, 2008; Ding, 2008; Cao, 2009; Xu, 2009). Similar interests in this area also emerge (Hu \& Wang, 2009) they adopt a sociological perspective and put insurance into social, economic and cultural contexts, then study the inter-relationship among them to consider the interaction between insurance and many other social, economic and cultural factors. However, such studies are still rather on the macro aspect and lack of empirical evidence, which gives rise to this study to investigate the more micro-aspect of insurance sales interactions in transformational rural China. Moreover, there are several problems in their research: To begin with, their research seems rather general and adopts a top-down approach. Secondly, most of their research is based on academic reasoning and previous literature, with very few offer empirical evidence, which might create a problem in its convincing effect. Thirdly, the stance they take is on the 
behalf of the organizations, they neglect the other side, that is, the agents in action and their clients. They take them as strictly passive recipients of the actions, which might not be exactly the case in reality.

Therefore, there is an urgent and imperative need which calls for concern in studying insurance that is based on sociological theories or concepts, yet can be analyzed into greater details and offer empirical evidence. The dialogues between insurance sales agents and clients, a contemporary genre situated on the boundary between public/organizational genre and promotional genre, are relatively under-researched and marginalized. The present study is such an endeavor intended to fill the gap and try to strike a balance between macro- and microstudies for the purpose of revealing the hidden world of insurance sales discourse in transformational China's rural areas. Swales and Rogers $(1995$, p. 239) indicate that studies of organizational genre "offer a dialogic middle way of thinking about social control and human agency, reproduction and innovation, coercion and resistance, model and instance, and linguistic form and institutional setting". Moreover, as Drew and Heritage claim, interaction is a dynamic process and language is a crucial resource for managing social relations at work (Drew \& Heritage, 1992, pp. 1-65), thus an interesting question emerges: how is language employed to serve the realization of insurance sales in rural China?

\section{Methods and Procedures}

Based on 10 authentic naturally occurring conversations between insurance sales agents and their prospective clients, the chief methodology is discourse analysis, focusing on conversational analysis at the micro-analytic level. In sociolinguistics or business English studies (Cameron et al., 1988; Planken, 2005) and cross-cultural/intercultural pragmatic studies (Bargiela et al., 2009), data are generally collected in a controlled and selective way and the focus is always on one or several types of speech acts. As Huo (2004, p. 69) noted, it is preferred that the type of data for such research be collected in a natural, uncontrolled way in that we did not confine ourselves to a certain type of data but include all instances of dynamics in our corpus. As Sacks et al. (1974), Heritage (1984), Jefferson (2004) and many other researchers (Duranti, 1998; Heritage, 1984; Hutchby \& Wooffit, 1998; Zimmerman, 1988), many analysts have studied mundane social action and have achieved desired results in such areas of discourse organization as turn organization (Boden, 1983; Roger, 1989; Schegloff, 2000a, 2001), Repair organization (Schegloff, 2000b). Other scholars study the structure of social interaction (Eggins, 1997; Yang, 1994; Lin, 2004), intra-cultural communication in various languages (Hayashi, 2003) and intercultural communication studies (Cheng, 2003; Scollon \& Scollon, 2001; Tanaka, 1999). Regarding Chinese data used in CA approach, most of it focuses on Cantonese (Kong, 2001, 2002, 2003; Luke, 1990). However, their findings on Chinese communication may not satisfactorily explain the interaction pattern and linguistic features specific to the Mainland Chinese due to the data they collect and use for their analysis.

The data collected are recordings of conversations between insurance sales agents and their prospective clients at their homes, tea houses, meeting rooms or other places where the conversations take place during 2009 to 2013 (about 80 hours, 50 conversations in total). The selected data for the analysis are 10 conversations between the 5 agents and their clients, while others are used for triangulation purpose. The data have been transcribed by the author himself according to the conventions of Conversation Analysis for discourse analysis purposes. Some of them involve two agents (the more experienced agent accompanies the less experienced one to visit their clients); some of them involve more than one client (their families or relatives may be present). In general, some of them involve two participants; some others may involve several participants since the conversations are rather informal in nature and there could be the prospects' relatives or friends present during the conversations. Their names, and some specific names of their products and their prices were replaced by pseudonyms or "X"s.

The procedure of analysis mainly starts from the transcriptions, followed by transcription study to identify some recurrent phenomena across the transcribed conversations. The procedures include:

Listening to the data — classifying the data — selecting the data — transcribing the selected data - studying the data for recurrent phenomena-in-depth discourse analysis of the excerpts by focusing on the phenomena-making cultural and linguistic interpretations of the analyzed phenomena-studying the interpersonal preferences - generating implications from the analysis.

The analysis is mainly qualitative, but supported by a quantitative approach with numerical evidence. A qualitative approach is applied first with an aim to discover and reconstruct patterns in insurance sales discourse. The data are examined for emerging patterns and language use that reflect the most striking features of the Chinese insurance sales agents in terms of discourse conventions, cultural patterns and values and linguistic manifestations in the sales process. The qualitative findings help to provide background information on the context and subject, acting as an aid for scale construction (Punch, 1998). The quantitative findings were applied to provide the basis for qualitative study with an aim to generate and frame the preferred patterns and linguistic 
choice in insurance sales discourse.

In the analysis, the author studied the organizational structure and corresponding linguistic features of the data, then the author examined the data by focusing on identified phenomena and counting the frequency rate of each feature/phenomena to generate the global structure of insurance sales interactions and generic socio-pragmatic preferences of the participants.

\section{Results and Discussion}

We found that insurance sales are promotional in nature. As many other promotional efforts, it shares some common features such as certain communicative purposes, moves and steps, however, it has some particular features of its own. Moreover, the agents are one member of the professional community of insurance sales, who are well aware of the intent, positioning, form and functional value of the communicative purposes through their training and experience sharing meetings, simply put, their socialization. They can consciously or sometimes unconsciously exploit such constraints in their interactions with their prospect clients to achieve their intentions of concluding the sales.

\subsection{Communicative Purposes}

Communicative purpose is essential in determining the genre category of any given material, as Askehave \& Swales (2001) put it, it "has been used as an important and often primary criterion for whether a particular discourse falls within a particular generic category".

We can summarize the communicative purposes according to Bhatia's summary of sales promotion letters (Bhatia, 1993) as follows:

- Insurance policies are generally addressed to those potential customers who are known to have some need (immediate or future) for the product or service being promoted. Therefore, the most important function of the agent-prospect interaction is to offer a clear, objective and attractive introduction to the products or service in terms of the perceived interests, needs or inhibitions of the potential customer.

- Due to the rampant advertisement present in everyday life and most interactions are unsolicited, the busy working people nowadays are not likely to bother to waste their precious time on such promotional efforts, thus the interaction must be short and effective, mostly repetitive. However, this requirement contradicts sharply to another: there should be enough details about the promoted product or service in the introduction for those interested customers who already have some need for or intention to buy the product or service. Therefore, the interactions vary according to different (prospective clients), nonetheless, most insurance sales are done between familiars in rural China, trust plays a significant role, and trust building process is time-consuming, therefore, the vast majority of the interactions are repetitive.

- Insurance agents serve as the first link or communication channel between an insurance company and a prospective client. In this respect, they are generally seen as initiating business relations between the two parties. Therefore, the initial interactions need to solicit further communication between the two parties. There should be some ways by which the insurance company can be contacted, in this specific context, the agent is seen as the embodiment of the insurance company.

With the above communicative purposes identified, for most of the time, the agents as one member of the professional community, they are well aware of the intent, positioning, form and functional value of the communicative purposes through their training and experience sharing meetings, simply put, their socialization. They can consciously or sometimes unconsciously exploit such constraints in their interaction with their prospect clients to achieve their intentions of concluding the sales. Next, it is important to discover the generic patterns in their sales efforts and communication with their (prospective) clients.

\subsection{Moves and Steps}

The moves and steps of the dialogues between insurance sales agent and prospective client can be generalized as follows:

Move 1: Warming up

Move 2: Introducing the offer

Step 1: Offering the product or service

Step 2: Essential detailing of the offer

Step 3: Indicating value of the offer 
Move 3: Offering incentives

Move 4: Establishing credentials

Move 5: Enclosing documents

Move 6: Soliciting response

Move 7: Using pressure tactics

Move 8: Ending politely

The above summarizes the moves and steps in the dialogues between insurance sales agent and prospective client, in terms of their flexibility, move 1, 2, 4, 6 and 8 are obligatory moves, while the others are optional ones. It differs from Bhatia's (1993) model for sales promotion letters in several aspects. First of all, for sales promotion letters, move 1 is establishing credentials, while for insurance sales dialogues, move 1 is warming up, this is the most significant difference between sales promotion letters and insurance sales dialogues.

Bhatia's (1993) seven moves analysis offers an excellent exemplar to refer to in the analysis of the dialogues between the insurance agent and the prospective client, it would prove quite useful and powerful in generalizing the general discursive patterns in the agent-client interactions. Consequently, the generalized generic patterns would be useful not only for the present study to lay its foundation of analysis in probing into the hidden world of insurance and the complex dynamics in transformational rural China, but also for insurance practitioners in improving their performance. However, owing to differences in oral and written language and the specific contextual factors, insurance sales dialogues in transformational rural China do have their own particular generic structure in terms of moves and steps despite the fact that both of them are promotional in nature, their similar communicative purposes of trying to achieve the sales of the product or service in general. For example, in insurance sales dialogues, there is this one obligatory move at each and every dialogue, that is, warming-up or greeting each other/small talk (hereinafter as warming-up), which is exactly one of the most interesting parts that reveals the dynamics of insurance sales in rural China.

\subsubsection{Warming Up}

The first move, warming up is the most distinctive and obligatory move in all collected samples and it has important functions. Move 1 is found in all the collected data, since the whole insurance sales is initiated on the basis of the familiarity between agent and client. Though move 1 can be in different forms, it is obligatory in nature, which serves as a starting point.

From the analysis of the dialogues and the sample dialogue above, the most striking finding is that in each and every dialogue, actually in each and every interaction between the agent and the prospect, it is imperative to have the first obligatory move - warming up, different from Bhatia's (1993) analysis of promotion letters with the first obligatory move as Establishing Credentials. It may be argued that this is due to the differences between written communication and oral communication. It is quite natural and important for people to greet each other before they talk about anything else.

\subsubsection{Types of Warming Up}

Warming up serves an important function in insurance sales agent-client interactions, and it distinguishes itself from other sales encounters. For most of the time, they appear in the form of phatic talk, while phatic expression, first introduced by Malinowski (1923) as one whose only function is to perform a social talk, as opposed to conveying information, or in other words, people use language to establish and maintain social contact in free, purposeless social talks. Such a view is echoed by Anthony (1964), "speech to promote human warmth", since for good or ill, we are social creatures and cannot bear to be cut off too long from our fellows, even if we have nothing really to say to them, and "phatic communication refers also to trivial and obvious exchanges about the weather and time, made up of ready-made sentences or foreseeable statements... Therefore, this is a type of communication establishes a contact without transmitting a precise content, where the container is more important than the content." (Casalegno \& McWilliam, 2004) Nonetheless, phatic communication serves as "important social lubricant" (Diana, 2002), in the words of Goffman (1967), "The gestures which we sometimes call empty are perhaps in fact the fullest things of all". Phatic communication can occur in three categories of the conversations, that is, at the beginning, at the end and at anywhere as a space filler. Phatic communication is of great significance for insurance sales communication in the sense that it is exactly, for most of the time, where Guanxi dynamics (local interpersonal relationships) perform. Now the specific types of warming up used in agent-client dialogues are summarized as follows.

Greetings. Most commonly seen between agent and client who are not familiar with each other or first time 
meeting introduced through a third party. "XXX, Hi!" ("XXX, Nihao a") or simply such expressions used with certain time limits as "Good morning" ("Zao a"), "Good afternoon" ("Xiawu hao"), "Good evening" ("Wanshang hao"), "Hello, uncle X" ("X diedie hao"), "Hello, aunt XXX" ("XXX Mama")......etc, moreover, there are some expressions with specific Chinese distinctiveness, "Teacher Liu" ("Liu laoshi"), "Aunt Li" ("Li ayi”), "Manager Qian" ("Qian jingli”).

Inquiry. For example, "Where are you going?" (“Ni dao naer qu o?”), "What are you doing?" (“Zai gao mazi?”), "Are you XXX? I am ..." ("Ni keshi XXXa? Woshi...").

In spite of seeming to have little useful purpose or any specific content, such phatic communication is a bonding ritual and a strategy for managing interpersonal distance. For example, in one encounter between the agent and client, the agent pays a visit to the prospective client's home, they don't know each other before and the prospective client is introduced by a third party that both agent and client are familiar with. The conversation goes as follows.
A: Nishi XXX ba? (Are you XXX?)
$B$ : An, Nishi nage? (Yes, and you are?)

A: Wojiao XXX, woshi Liu laoshi jieshao laide, ta zuowan geini dale dianhua leba? (I am XXX, I'm referred to by Teacher Liu, did he call you last night?)

$\mathrm{B}$ : O, shide o, ta genwo dagai jiangle xiazi, ni jiushi XXX o. (Oh, yes, he talked to be briefly about that, you are XXX.)

A: An, hehe, wo jintian ganghao guolai, jiu xianglai Kankan, genni guagua—fanzheng bu yaojin, liaojie xiazi duhao a. (A, yes, Hehe, I just came by to have a look, to talk to you —it doesn't matter, you can have some brief ideas.)

B: An, haoa. (Yes, OK.)

A: Woting Liu laoshi jiang ni xiangmai... (I heard from Teacher Liu that you are willing to buy...)

(Continues the talk on a specific policy)

At the beginning, Nishi XXX ba? (Are you XXX?), this simple inquiry is a self-answered inquiry, since the agent has been almost certain that is the one she is going to talk to. It serves as a starting point to open a dialogue to define the relationship between the agent and prospect as new acquaintances introduced through a third party. Wojiao XXX, woshi Liu laoshi jieshao laide, ta zuowan geini dale dianhua leba? (I am XXX, I'm referred to by Teacher Liu, did he call you last night?) in this way, it helps new acquaintances to explore and categorize each other's social position. In this conversation, "Liu laoshi" (Teacher Liu) has an extremely important role, since he is friends of both the agent and the client, he serves as the bridge to introduce both parties to know each other and carry on smoothly the interaction, such a way of operation can be best captured by Fei Xiaotong's "differential mode of association" (Fei, 2007) in rural China's network.

Comment/compliment. For example, "Guniang shou xiaoqiaoqiao de" (This girl's hands are little and cute), "Xiegui hao haokan" (You have very beautiful shoe cabinet) "Aye, ni guode zhenhao" (Wow, You look so well), "Guaiguai, nijia de fangzi zhen piaoliang" (Wow, you have so beautiful house).

The following is another reconstructed example in which an insurance agent tries to sell policies to one of her friends, who is not so interested at the very beginning of the conversation. The insurance sales agent is the kindergarten teacher of the prospective client's granddaughter. B (the prospective client) is one of the peasants under A's husbands' (A's husband is the village director) (Note 1) management. A (the agent) and B (the prospective client) are talking about the little girl, who is B's granddaughter. The following script is an excerpt from a longer conversation; the conversation is transcribed in the local dialect.

A: Liu ayi zai jiali a? zheshi ni sunnvr ba? Xiao guniang shou xiaoqiaoqiao de, xiaode henzi. (Aunt Liu, you are home. This must be your granddaughter, she has little and cute hands.)

B: Xiaoqiaoqiao de a. (little and cute...)

A: Xiao guniang shou xiaoqiaoqiao de buyaojin... tade shou piaoliang, nikan tana xiaoshou. Zhe xiaoguniang zai women ban, jiu tade shou zui haokan. (It's good to have little and cute hands, you see, how beautiful hands they are. She has the most beautiful hands in our class.)

B: Haokan you shenme yong? Nianshu you bu guojing. (There is no use to have beautiful hands, she is not doing well in her study.) 
A: Xiaoguniang de shou shengde hao yao haoxie, hehe, jiu jueding mingyun le... hehe, shou youxie jiangfa. (For little girls, having beautiful hands is a great blessing, sometimes, it determines destiny... there is some saying about hands.)

B: Najiu bu xiaode shi shenme yangzi lo. (I have no idea about that.)

A: Tade shou shengde hao, (pause), nide maomao baoxian banle meiyou? (She has beautiful hands, pause, did she buy insurance?)

B: Shou zhege dongxi nage jiangde qingchu? Hehe, nijia Wang Wen xianzai nian gaozhong le... (Who knows about hands? Hehe, so your son Wang Wen is already in senior middle school...)

A: En, shide o, rizi guode zhenkuai. Wojia Wang Wen ye maile baoxian, nijia maomao zenmeyang a? (Yes, time flies. Wang Wen has already bought insurance, how about your girl?)

B: Baoxian na? Baoxian ta mama zhunbei geita gao. Qunian zhaota baba, baba shuo guonian jiang, guonian houlai wo youmang, mangdao meiyou laile. Jinnian buzhi gaole meiyou, ruguo yaogao, ta kending yao genni jiang. Haiyou nage nage genta baba jiangle, taba mei daying. Jiangle, tashuo yaojiao haoduo nian laizhe? Yaojiao shinian ba, shinian dao shiba sui naqian ba. Tingta xiang nayang jiang, wo erzi jiangshuo xianzai jingji bu huofan, buxiang gao. (Insurance? Her mother was thinking about it. Last year, someone approached her father and he said next year. After the new year, we've been busy. I don't know for sure whether we have had it already. If we are to buy, it's for sure he will come to you. Someone actually has approached her father, her father turned her down. It seems we need to pay for ten years? Then we have some payback, seems so. But my son says we are in tight budget, maybe later...)

A: O... Xianzai henduo ren dushi gei xiaohai gao, dengyu gei xiaohai cun yibi qian a. (Oh... Many people are buying it for their children, it's savings for them.)

B: Shide a, xianzai xiangzhe qingkuang gao yehao, dengdao xiaohai dushu... (Yes, now it's a good time, when she goes to school...)

A: Fudan yao haodian. (It can relieve us a little.)

B: En, Fudan yaohao. (Yeah, relieves a little.)

A: Yinian jiao liangsan qian ye wusuowei... ta qiannian ganghao jiang wu gaole, qiannian ne, qiannian ne ye mei chuqu, zhe qunian cai chuqu gaole yixia, ta gaodian qian you maige dianpingche, you zhige bingxiang, en, jiali zhi dongxi. (It is not that heavy burden if we pay several thousand Yuan. He has got the house refurbished last year; and the year before last, he stayed at home. Last year he went out to work and bought one electric bike and a refrigerator, and bought furniture as well.)

Conversation continues, talking about the girl's mother, job and others...

As introduced in the background, A is the kindergarten teacher of B's granddaughter, it sets up a complicated scenario as the agent A mentions B's granddaughter, she uses the privilege of being the teacher of B's granddaughter, moreover, it is their mutual knowledge that A is the wife of the director of the local village, such phatic communication creates a complex scenario that both parties are aware and are willing to maintain, it is expressively communicated but impressively communicated. The sentence "Xiao guniang shou xiaoqiaoqiaode" (The little girl's hands are little and cute "Tade shou piaoliang" (Her hands are beautiful) "Zai women ban, jiu tashou zui haokan" (Her hands is the most beautiful in our class). They are compliments and thus phatic communication in nature, however, they serve much more than the purpose of phatic communication, which will be argued in greater detail later.

Retrospect. For example, "Haojiu bujian" (Long time no see).

As argued all through the thesis, the insurance sales are achieved through Guanxi in transformational rural China, most of the interactants are either friends, relatives, familiars or at least introduced through a third party that both agent and prospective client are familiar with, thus, initial small talks to smooth up the atmosphere is an essential part of the successful conclusion of business. Since the degree of trust that the agents establish is one of the deciding factors of the success of their sales, as in the above sample, "Zhege xiegui shanghao piaoliang de o" (This shoe cabinet is really beautiful). In this setting, the client's husband is a carpenter, praising one of his works will definitely have a favorable impression on the client, and also a hidden message is entailed in this sentence - a carpenter with good craftsmanship will of course be relatively better off, it is time for them to think about having more additional well-being besides their living standard, that is insurance will offer them a better guarantee for their future life 


\subsubsection{Functions of Warming Up}

As Malinowski (1923, pp. 149-150) observes, it is "free, aimless, social intercourse", which is manifested in exchanges characterized by "purposeless expression or preference of aversions, accounts of irrelevant happenings, comments on what is perfectly obvious", such exchanges have the important social function of creating ties of union by mere verbal exchanges, "the ties of the moment without which unifies social action is impossible" (ibid., p. 149). While in rural insurance sales, such an atmosphere of sociality and interpersonal communion is of crucial importance to the successful conclusion of business, i.e., the insurance sales. In this specific context, the little girl is the target of insurance sales (the proposed policy is for her), it would be wise to start a conversation related to this little girl, it creates "the pleasant atmosphere of polite, social intercourse (ibid., p. 152), or establishes "rapport" between the interactants, thus facilitates the promotion of insurance sales.

Insurance sales in transformational rural areas distinguish itself from normal sales in product or service encounters, especially in warming-up, for example, the following is a short segment of a dialogue between a sales assistant and a customer in a convenience store.

Context: The sales assistant, male, does not know the customer (also male), they are strangers; both of them are in their thirties.
A: Sales assistant B: Customer
B: Ni zheli you baiwei pijiu ma? (Do you have Budweiser here?)
A: You a. (Yes)
B: Zai nali? (Where is it?)
A: Bingde haishi bu binged? (Iced or not?)
B: Bingde. (Iced)
A: Zai zui limian de binggui li. (In the frig down the shelf.)

(get the beer and come to the cashier.)
A: 22, xiexie. (22, thank you.)
B: Hao, geini. (OK, here you are.)

From this short segment of sales encounter, both of the participants are rather direct and to-the-point right away in the whole process, there is no warming-up at all, they don't have any social talk or friendship talk, both of them are very succinct and brief, yet the communication is still successful in nature, in terms of the outcome-successful conclusion of business. It is a customer-initiated talk with the customer's direct inquiry of "Do you have Budweiser here", very little or even no facework is found in this utterance. In the meantime, the sales assistant responds only the essential information with very brief "You a" (Yes). This response and pattern of interaction can, to a certain extent, illustrate that there is no much need for further and deeper or continuous interactions between the sales assistant and customer. The sales assistant's behavior is characterized by brief responses, lack of facework, and unwillingness to do anything beyond his routine (for instance, his only inquiry to specify the customer's need, "Bingde haishi bu binged?" (Iced or non-iced?) and his far too brief answers to the questions, "You a" (Yes, we do) "Zui limian de binggui li" (In the frig down the shelf). In short, both of them do not imply any face-redressing strategies. Even with the last short segment of "Xiexie" (Thank you), it is considered as very routine and habitual in sales or service encounters nowadays. Another reason for the above pattern of politeness behavior could relate to their mutual expectations of relationship continuity. The fact that the sales assistant didn't take care much of the customer's face is due to their mutual expectations of their relationship continuity. The sales assistant understands that the relationship with the customer is short-term. And it is also similar for the customer, both of them are aware that this relationship may not continue in the future. As a result, the sales assistant does not have the adequate motivation to build up rapport with him. However, it contrasts sharply with that of insurance sales in transformational rural China. If an insurance sales conversation goes like the above sample, it's very likely it would go wrong. It would be considered as rude, greedy, inconsiderate and impossible. Regarding this, one of my informants confesses as the following: "Qishi women zuo baoxian jiushi zuoren na, yaoyou naixin, yaogen kehu manman gua... zaizhe changzi, zuo shiqing yebu rongyi, dajia dushi taitou bujian ditou jian de, na zenme hao yisi o" (Actually we sell insurance by making friends with others, we need to be very patient, and talk to the clients slowly, step by step. It's not easy to sell insurance here, we are all familiar with each other and see each other frequently, and it would be a shame - if we are too direct). It can be seen from the confession that relationship plays a vital role in successfully concluding the business, even to a certain extent, the success or failure of the sales effort largely depends on the rapport built 
between the insurance sales agent and the client, and the social resources the agent possesses, especially in transformational rural China. In a word, Guanxi is not only emotional, but also instrumental in transformational rural China.

After the opening-up and reform, the economy developed very quickly with the increasing level of people's living standard, at the same time, some of the resources are not easily accessible in people's work. Thus it would be important to establish an instrumental interpersonal relationship on the basis of interest. Under the current circumstances, the number of people you know and the capability of getting things done have become one major criterion in evaluating the social resources that one possesses. In this kind of society, people tend to forge a kind of relationship which might bring some benefit to them, even though sometimes this kind of relationship realizes its role in the distant future. Insurance sales in transformational rural China conforms itself to the instrumental nature of the Chinese interpersonal relationship, as clearly iterated by the agent, "making friends" "talk and work slowly", etc.

The training sessions and experience sharing meetings, or the socialization process of the insurance sales agents also attach great importance to warming up, for example, in one informal experience sharing meeting of the agents, the one who had excellent performance says (in her forties with about 15 years experience), "Qishi women zuo zhege dongxi, man zhongyao yidian jiushi yao chayan guanse. Kaishi de shihou buneng taiji, ni yueji ni kehu keneng jiu yue fangan; jiang zhende, zai nongcun zuo baoxian bu rongyi, jingying kehu yiding yao yongxin, yao zhenzheng bat amen dang pengyou laichu, jiao pengyou le, jiaoxin le, caiyou jiaoyi. Jingchang youshi meishi zhao tamen guagua, zhao yiqie jiekou gen tamen jiaoliu, fanzheng zongyou jihui jiu jieshao dema. Zui zhuyao tamen yao xiangxin women, xiangxin baoxian, xiangxin gongsi. Haiyou yige yao xixin, kehu baifang ziliao yiding yao jilu hao; yijing chengbao de kehu ziliao fenlei zuzhi hao, biru wode kehu, shengao tizhong shouru jiating zhuangkuang wo duyou feichang xiangxi de jilu, suoyi buguan dao nail, zhexie ziliao suishi duneng chadao. Lingwai yige taidu yao zhenzheng. Fanzheng buguan zenmeyang, yaozhao jihui gen tamen la jiachang, yao dadong yixie kehu. Zhexie xijie yao tebie zhuyi, lajin yu kehu zhijian juli, houmian goutong jiu rongyi le. Biru jiang tamen jiali de qingkuang, haizi a, fumu a, fanzheng yiding yao zhaodao yige qieru dian." (In this business, a very important point is that we need to be observant. You can't rush to conclude the deal, more haste, less speed. To tell the truth, it's not easy to sell insurance in rural areas, we need to be fully devoted to our clients. We need to really consider them as our friends, only after we have been friends, exchange hearts, can we have deals. Talk to them, talk to them whenever possible, we always have a chance to promote. The most important thing is that we need to have their trust in us, in insurance and in the company. For another, we need to be careful and well-organized. We need to keep a good record of the clients' information, such as classification, height, income, family status, etc. Thus, wherever we are, these data are always accessible. Still another is that we need to be sincere and honest. We try to talk to the clients, move them, pay attention to details, get the relationship closer and more intimate, it'll be much easier for later and further communication; for instance, we can talk about their family status, children, parents, etc., all in all, find something in common and grab an entry point). In this segment of experience sharing, such units as "sincerity" "trust" "friends" "observant" "patience" "keep visiting" "whole-heartedly" are clearly highlighted. As Sun (2009) iterates, "Guanxi is established on the basis of the concept of 'reciprocity', it is reciprocal in nature. What one does in other's interest is considered as a kind of 'social investment', it is obvious he/she expects something in return (Sun, 2009, p. 26)." Simply put, one salient feature of Chinese interpersonal relationship is its instrumentalism.

To summarize, warming up in rural insurance sales is an indispensable part of the successful conclusion of business, it builds up rapport, facilitates the communication and paves the way for smooth communication between the insurance agents and their prospective clients, moreover, it is based on the social concept of "reciprocity".

\subsubsection{Introducing the Offer}

Move 2, introducing the offer, is the most important move of all the moves in agent-client interactions, and it is an obligatory move which takes up the vast majority of the time of the interactions. The success or failure of the sales mostly depends on the effectiveness of the introduction.

Step 1 of move 2, offering the product or service, is the formal initiation of the sales effort, and is the first time the topic of business brought up. In the sample above, "Ni nage zenme jiang o" (How do you think about the insurance we discussed last time?) is the indirect way of bringing up the topic, since they have already met for several times before and both parties are well aware of what they are talking about. It seems in the local settings, direct mentioning of insurance and money is dispreferred, which may due to the maintaining of face between the interactants. The concept of face, central to Brown and Levinson's $(1978,1987)$ theory, is derived from Goffman 
(1967) and the English folk terms "losing face" and "saving face". The theory assumes that all competent adult members of a society are concerned about their face, the self-image every member wants to claim for himself or herself and recognizes others have. Brown and Levinson further distinguish between negative and positive face wants. Negative face refers to basic claims of territory, freedom of action and freedom from imposition. While positive face refers to the desire of being appreciated and approved by others. It is in the reciprocal interest of the participants in conversation to maintain each other's face, there are in total five strategies offered:

Bald on record, without redressive action

Positive politeness

Negative politeness

Off record

Don't do the face threatening act (FTA)

It is noted in the sample conversations that the fourth strategy "off record" and the fifth "don't do the FTA" are most frequently employed among others, throughout the conversation, it is rarely direct asking of purchasing, however, such an idea is implied and reinforced throughout, for example, "Nikan ye huabuliao duoshao qian" (You see, it does not cost much) "Fentan dao meige yue, jiu jibai kuai" (Distributed to each month, just several hundred Yuan)

Step 2 of move 2, essential detailing of the offer, "introducing and explaining the specific terms", in this way, the prospective client would have a better understanding of the specific clauses, rights and obligations. Of course, as van Dijk (2006) argues, there are certain strategies adopted in the detailing, for example, emphasize the benefits and downplay the detriments, all in all, creating a favorable impression on the part of the prospective client.

Step 3 of move 2, indicating value of the offer, is the most important part of all the introduction, all the efforts, either directly or indirectly, serves the purpose of emphasizing the value of the offer. For example, the sample dialogue, the agent distinguishes the insurance under discussion with rural cooperative medical insurance by emphasizing the deposit function of the insurance. "Women zhege you liangge gongneng, you cunqian you baozhang" (This insurance has two functions, not only it offers coverage for medical care, but also some deposit"; for another, "Nadian qian gao shenme dongxi o" (You can't do much with that little money) "Cha zhe liangqian kuaiqian buguo rizi la" (Two thousand Yuan is nothing much) emphasizing the much lower cost and much greater benefit that it brings; more detailed, "Jiaru jianjian kangkang de, ershi nianhou geini 9wan; wanyi youge shenme shiqing, mashang geini 9wan, hetong zhongzhi. Ruguo you zhongda jibing, yibao nabian zhaoyang bao. Zhege baoni yibai sui, jiushi ni huo duolao bao duolao"(If with good health, you'll get 90000 after 20 years; if anything happens, you get 90000 right away, and the contract terminates. If there are some major diseases, you can get reimbursed with your social security as usual. This one covers your whole lifetime, i.e., as long as you live), "Qishi naqian fangzai nali yejiu fangzhe le, maile yihou ruguo ziji youdian yali faner haishi haoshi" (In fact, it's a kind of deposit, it's good to have some pressure), "Ni xiang women xianzai du sishi laisui le, manman nianji dale, ye gaobudong le" (We are in our 40s, and getting old and weak, cannot work as we were young), "Women suiran shi funv, yeyao gei ziji xie baozhang a, wanquan kao renjia ye dushi kaobuzhu, zui qima ziji you yidian, haoxie ai" (Though we are women, we need to have some assurance. It's impossible to completely depend on others. It'll be a better idea we have certain amount of money of our own), "Xiao jiaohuo fudan ye zhongde budele, fangjia duogui" (Our children will have heavy burden themselves, with so high housing prices) "Qima haishi bugei tamen zengjia fudan a, duoshao youge baozhang" (At least we don't exert further burden on them, we have already got some assurance ourselves).

All in all, in this part, the agent employs mainly the strategy of "emphasizing the benefits and downplaying the detriments" by essential detailed introduction of the specific policy in question. All the interactions are centered on the purpose of persuading the client to make the purchase decision.

According to Montgomery's (1988, p. 353) model of "Ideals of Relationship" and Rogers \& Miller's (1988) maxims of friendship engagement, it is crucial for parties in communication to observe and practice the maxims, no matter consciously or unconsciously. In the communication between agents and clients, the agent consciously employed the maxims. For example, the Maxim of Trust, be sincere and be empirically veracious. The agent objectively describes the abstract insurance clauses and coverage for the client, presenting an image of being a professional insurance agent, but at the same time, delivers the message in the local dialect, convenient for the understanding of the client. Such expressions as "Women suiran shi funv, yeyao gei ziji baozhang" (Though we are women, we need to have certain assurance) "Ershi nian hou geini 9 wan" (Ninety thousand for you after twenty years) "Gei ziji yidian yali faner shi haoshi" (Sometimes it's good to have certain pressure)"Nianji 
manman dale, gao budong le" (We are getting old, we cannot work for long), "Duoshao youge baozhang"(It's an assurance anyway) clearly reveal the maxims of Trust, Intimacy, Control and Positiveness.

\subsubsection{Offering Incentives}

Move 3, Offering incentives, is an optional move in the dialogues, it occurs when such policies are rather larger in amount or there are some promotional efforts, the additional bonuses are normally some household apparatus, such as quilt, pot, electric blanket, etc. For example, "Ruguo jintian xiadan women you XX lipin song" (If you sign the contract today, there will be ... presents), "Xiadan dadao XX shue, jiuyou yitao XX jinian bi" (When the contract value reaches ..., there will be ... presents), "Genju butong jine, xianchang xiadan you beizi, weibo lu, dian chaoguo, huoguo lu, dianre tan song" (According to different contract value, we have different presents). This move is optional in that for most of the time, there is seldom such incentives, they mostly happen when there is a promotion meeting on site, that is, some prospective clients will be invited to a certain location (such as a fancy hotel, a local school, the hall of a company, etc) to carry out a promotion, the process goes like this, first the agent will seek support from the company, then some renowned lecturer of insurance or beneficiary of some insurance policies be invited to introduce (educate) the participants about the importance of insurance for their lives, the visible benefits they have received and enjoyed, clear contrast between having been insured and not having been insured offered, of course sometimes, the clients are also attracted by the additional benefits of the gifts, which has already become a popular promotional method widely employed by institutions.

\subsubsection{Establishing Credentials}

Move 4, establishing credentials is also an important move in realizing the persuasion process in insurance sales in transformational rural China, the following offers evidence from the transcriptions of dialogues and also interviews with the agent.

\subsubsection{Establishing Credentials and Trust}

Move 4, establishing credentials is an obligatory move and is found in each and every of the conversation. It plays a vital role in the successful conclusion of the insurance sales, since the establishment of credentials is the foundation of trust, meanwhile trust is the pillar stone in the conclusion of insurance sales. Trust can be classified into "interpersonal trust" and "institutional trust", "particularistic trust" and "generalized trust" (Zhao, 2013; Liang, 2011; Luo \& Ye, 2007), in which interpersonal trust corresponds to particularistic trust and institutional trust corresponds to generalized trust. Since particularistic trust is also called personal trust, which refers to a particular dyads trust relationship and is the outcome of the interactions between the two parties, if there is no acceptance and reciprocity from both parties, there would be no trust. In many circumstances, people would prefer someone familiar or someone who can trust, as a manager of a private company says, "I'd rather do business with good friends for only 200,000 Yuan profit, than for 500,000 Yuan profit with someone without trust (Yang \& Peng, 1999)." Such a statement expresses the earnest concern of the Chinese people when it comes to business, since if there is a lack of trust, the party concerned would have to shoulder so enormous risk that he/she could even lose the investment once and for all. In the context of insurance sales in transformational rural China, trust also plays a vital role. The trust is established, maintained and even enhanced not only in the actual dialogues, but more importantly in the casual interactions between the agent and the client. As one experienced insurance agent once put it in one interview sharing her experience in successfully concluding a major policy, "Zhege kehu qishi zhiqian feichang fangan baoxian, ta dui baoxian keyi jiang yidian xiangqu du meiyou, danshi wo zhege ren shi zheyangzi de, wo kanzhun lede shiqing wo yiding hui quzuo, nawo jiu jingchang youshi meishi zhaota ma, zhaota gua, kaishi qishi ta men du burang wojin, nawo jiu guancha, wojiu faxian tajia youge xiao never, zhangde haode hen, you yici yige ouran de jihui wojiu xiaode le ta never shengri, wojiu paodao chaoshi maile yige xuexiji, nashihou xuexiji mangui deai, jiushi nazhong yina jiufa shengyin de nazhong a, haineng xue yingyu, wojiu songgei ta never. zhe xiazi haole, yinwei tamen gongzuo manga, mei shijian xiang zhexie dongxi, nawo jiubang tamen jiejue le zhege wenti, houlai jiang ta never xihuan de budele, tiantian wan; zheyangzi manmande, tajiu jiawo weixin le, nawo jingchang zai weixin shangmian jiang a, xuanchuan a, ye jiushi yige qianyi mohua de xiaoguo, bannian duo shijian ba, houlai you yici tajiu zhudong zhaowo qianle yige shiwan de danzi. Xianzai xiangxiang, qishi yejiushi zuoren, xian jiaoren, zai jiaoxin, zuihou caishi jiaoyi. Dangran jiaoyi women ye bushi jiang yi chuizi maimai, houmian ta you shenme xuyao, wo zongshi jinxin jinli qu zuohao fuwu." (This clientactually didn't like insurance at all, he had no interest in insurance. But you know me, I am determined to have it done once I'm in. So I noticed he has a beautiful little daughter, once I got to know her birthday, I bought a learning machine for her as a birthday present. Since they are too busy to think about their daughter's study, I happened to solve the problem for them. I heard that the daughter loved the present a lot. Then gradually, we became friends on Wechat, I gradually made certain efforts in promoting the products. About 
half a year later, he purchased a rather substantial policy from me. Now when I look back, I firmly believe it's about making friends, making us trustworthy. It's not a once and for all job, it takes a lot of patience and time. Even now, if there is anything I can do for them, I still do it.") (Interview, February 2013).

The above interview is a typical example of persuading successfully a prospective client, who was resistant to insurance at the beginning and finally after trust between the agent and the client established, concluding a major insurance policy $(100,000$ is considered as a rather large sum with the local standard). "Youshi meishi zhaota" (Casual chat), "Zhaota gua" (Talk to him), "Bang tamen jiejue wenti" (solve problems for them), "Zheyang zi manman de"(Slowly this way), "Qianyi mohua" (Exert imperceptible influence), "Zuoren" (Making friends) "Xian jiaoren, zai jiaoxin, zuihou caishi jiaoyi”(Making friends, being trustworthy, and deal at last), "Bushi jiang yichuizi maimai" (It's not a once-and-for-all deal) are all clear manifestations of the central role of trust in insurance sales in transformational rural China.

Establishing credentials in the actual dialogue is an obligatory move. It includes both the credibility of the agent and the insurance company that offers such policy. For example, "Ni xiaode wo" (You know me) "Women zai zhebian ye bushi yitian liangtian, you shenme wenti, ni daoshihou lai zhaowo" (We are here not for just one or two days; if there's anything, you can come to me any time) "Shijie wubai qiang, zhongguo zuida baoxian gongsi" (World top 500, China's largest insurance company), "Canyu xibu da kaifa" (Take part in the development of the west), "Zai shijie gedi duyou da touzi" (Major investment around the world). All such expressions serve to establish the credentials of not only the agent him/herself, but also the company, by presenting a credible, trustworthy and helpful image.

\subsubsection{Other Moves}

There are other moves, move 5, enclosing documents, soliciting response, using pressure tactics and ending politely, among which, enclosing documents and using pressure tactics are optional, while the other two, soliciting response and ending politely are obligatory. It is quite evident that soliciting response should be obligatory, since the successful conclusion of the policies, as mentioned, for most of the time, requires several or even more visits of the agents to the prospective clients, thus it's crucial for the agent to make sure further future communication is possible. Some examples of each of the above mentioned moves are listed as follows:

Move 5, enclosing documents is an optional move, in this specific sample, "Wozhe changzi youge jianyishu" (We have a suggestion form here). The purpose of this move is to enable the clients to have a more detailed understandingof the insurance policies under promotion later on their own.

Move 6, soliciting response, is an obligatory move, since the successful conclusion of the business usually takes rounds of visits and interactions. It is rather rare that the agent can secure a conclusion of business by just one visit, thus further communication is vital in their sales performance. Just as one of the agents recalls "Xiang yici chenggong, na jiben butai xianshi, yiban dushi yao pao hao jici, ni buba guanxi gaohao, hai gao ge gui a?" (It's not likely that you succeed by visiting once, we need to visit multiple times. Without making the relationship reliable, it's impossible).

In the above sample dialogue, "Zhe changzi youge jianyishu, wo liudao zhe changzi, xiamian youwo shouji, nimen dao shihou shangliang haole geiwo dianhua wojiu dao shihou gan guolai jiu zhongle." (I'll leave this suggestion from here, you can have a look, if there is anything in need, call me). Such expressions make due preparations for the next round of visit, and make the visits natural and casual to the prospective clients.

Move 7, using pressure tactics, is an optional move. This move should be employed with caution, because it is very likely that it might invoke antipathy from the part of the client. Nonetheless, sometimes it is also necessary to fasten the client's decision process, as one of the agents says "Youde shihou yao jinliang jiao tamen kuai yidian, biru jiang women youde baoxian you shijian qixian; youde you dongxi song, na dangchang qiandan jiuyou, wan yidian jiu meide lema" "women youde shihou jiang mouxie baoxian zhi zhendui teding kehu, biru jiang lao kehu, huozhe tamen leiji de baoxian maidao duoshao a, nazhong" (Sometimes we also urge them, for example, a time limit; some with presents, but only for those who sign on site; certain policies are only reserved for quality clients" etc).

In my observation, it is only used when the prospective client has almost made his/her mind in making the purchase. Specifically in the sample above, "Xianzai zhege baoxian youge tuiguang qi, zaiyou yige yue jiu meiyou le" "Nage XX women jiu tuiguang le jige yue, xianzai jiu meiyou le" (There is a promotion period for this policy, which lasts for only a month" "This XX has only several moths' promotion period").

Move 8, ending politely, is an obligatory move. Generally they are small talks again, "Nahao, women jiu zheme jiang, dao shihou zai lianxi" (OK, let's keep in touch). The topics vary, they could be children, education, 
decoration, family, life, troubles..., all in all, such ending would make the conversation more like that happens between friends, which will be analyzed in greater detail in the next two chapters.

This move, ending politely, normally centers around such topics as family, children, education, in short, small talks, which serves important functions as well. It echoes the beginning move of warming up, serving the purpose of strengthening rapport and laying a solid foundation for future further visits. "Making friends first, doing business later". To a certain extent, the establishment and maintenance of "ego-centric social network" (Zhao, 2013) facilitates the insurance sales in transformational rural China, on the one hand, it requires constant, frequent and careful attention as well, which on the other hand illustrates the nature of Guanxi being reciprocal. In this particular context, the conviction, determination and devotion of the insurance sales agent will largely determine the success of the sales efforts.

\subsection{Some Discussions}

It has been generally accepted that the more modern the society is, the more institutional trust people have. Institutional trust is a kind of trust based on the guarantee of institutions, and therefore, people tend to have greater faith in people's general liability and responsibility. With the reliable and widely acknowledged institutional guarantee, even the behaviors of strangers are completely predictable (Zhao, 2013). Nevertheless, in insurance sales in rural China, due to the fact that it is operated with interpersonal trust, moreover, with the impact of economic tides, there are some irregularities, abuse or even purposeful manipulation of interpersonal trust, which is also one of the concerns of the present study. For example, some people hold that the overuse of trust in local communities tends to compromise the social integrity and thus increases the cost of interpersonal communication. This is especially true when it comes to a society in which interpersonal trust overweighs institutional trust (Chua, Morris, \& Ingram, 2009; Tang \& Huhe, 2014), which consequently gives rise to Guanxi manipulation or backdoor activities (Lee \& Dawes, 2005). Nonetheless, based on the data I collected and what I observe, we do not tend to impose value judgment upon such complex phenomenon, what we can do is to present the facts and uncover the dynamics operating under the interactions. A more balanced view of not only trust, but also Guanxi seems to be more appropriate. As argued by Liang (2002), "In the Chinese society, 'Guanxi' is a very local, complex and delicate concept, it is very useful even when dealing with official institutions, the sophistication is far greater than the official formal bureaucratic institutions featured by their complexities."

Due to rapid social change or social transformation, the old social order is under severe impact and challenge, as nicely put by Fei $(1999$, p. 316), "A more pressing crisis of mentality order". The most conspicuous manifestation of order crisis is that old system is under constant and comprehensive challenge, while the new one is far from being established to affect people's daily lives. Old system and new plan, old customs and new trends, old concepts and new vocabulary, they all co-exist and interact with each other. Though "the blending of new and old style, modern and traditional, are distinctive characteristics of transitional society" (Riggs, 1964, p. 14). Apart from the mechanism of the market economy, the most successful part of reform and opening up is that it boosts the wisdom and initiative of the whole society through the incentives of personal interest, meanwhile, it generates money-worshiping as well.

With reform and opening-up and forthcoming market economy, tremendous changes have taken place in China's society; while such changes have not only significantly improved people's livelihood, but also made some people's over-reliance on speed. Moreover, the over-emphasis on economic development rate, especially the worship towards GDP, make people nationwide motivated by such concepts as "overtaking other countries" "overtaking other areas" "overtaking others". The worship towards "Shenzhen speed" "High speed rail" and "GDP growth rate" actually reflects the aggregating anxiety and unrest. Simply put, the more we change, the more we are longing for change, the more we long for change, the more slowly we feel changes take place. Such anxiety permeates the whole society, even in the rural areas. As manifested in insurance sales, the sales agents push forward hard their selling efforts into concluding policy sales, and they work at the interface of institutional trust and interpersonal trust.

As has been generally agreed that the Chinese society is a society of familiars, a "differentiated mode of association" (Fei, 2007; Zhai, 2007), people tend to categorize different people into different groups characterized by so called "insider" versus "outsider". It is argued that the Chinese culture builds its foundation on the basis of agriculture as its economic foundation. While this kind of self-sufficient lifestyle restricts mobility and constrains that people are "attached to earth" and "depending on land", which consequently also account for some moral qualities of the Chinese people, particularly, the virtue of patience and great importance attached to reputation. On the other hand, industrial world attempts to shorten the period of time needed for 
production, it requires everything to speed up. In China's rapid process of transforming itself from an agricultural society into an industrial society, diverse and various concepts and ideologies interact and collide with each other. As we have argued, with the old system demolished and the new one yet to be established, there is a growing confusion and not knowing what course to take. It is represented in the mal-practices of some insurance agents' ways of promotion of policies. For example, they solely emphasize the advantages, purposefully ignore the problems or even some hidden clauses not in favor of the clients, or consume on their credibility and integrity established over time. For which, in the author's view, are necessary process and pains we need to undergo and can echo, to a certain extent, the post-modernist view of "commodification of self". The process of growing mature in the agents' socialization process indicates that the ultimate harmony not only between agents and clients, but also how the agents can live with themselves in peace would largely depend on a naturalistic view of "nature does nothing, but everything is done". As the philosophy of Taoism upholds, simplicity and a naturalistic view of life are the ways of nature, and should also be the way of man, given the complications of modern life. Associated with the principle of simplicity is the attitude of contentment towards material living. Only one is contented with what he/she has and lives with it, can he/she live in peace deep in their heart. However, this contradicts sharply with the modern view of industrialization, exploitation as much as possible. One may criticize this view of life as a form of asceticism which may not fit the life of a highly developed civilization. However, contentment is not the same as the denial of any enjoyment at all. A life of contentment is a life free from frustration, anxiety, and sense of misery. Once a less extreme and more moderate view is established, most of the conflicts and disputes can and will be resolved.

\section{Summary and Conclusion}

From the above analysis, the study analyzes the discursive patterns and functions of moves and steps, in the interactions between insurance sales agents and their clients in transformational rural China. Specifically, we have summarized the specific communicative purposes of insurance sales dialogues. With these communicative purposes in mind, the analysis model for the generic structure of insurance sales dialogues is offered and analyzed. Consequently, the underlying cultural sources that account for the features are interpreted according to the functions in the collected data.

Secondly, the study has enriched the socio-cultural study of transformational rural China in examining insurance sales agent-client interactions in terms of exploring the discursive features in such interactions. In other words, money has become more important in rural Guanxi, as manifested in language, more specifically, discursive features. As most of the current studies of transformational rural China, either focus on ethnographic study or logical reasoning. In contrast, this study manages to incorporate macro-analysis of socio-cultural environment with micro-analysis of more detailed discursive features in insurance sales interactions in transformational rural China.

Thirdly, by integrating modern social theories and concepts (Fei, 2007; Zhai, 2007, 2009; Cao \& Chen, 1997; Sun, 2001; Lu, 2002), we describe and generalize the communication patterns for insurance sales in transformational rural China, in the meantime, come to uncover the hidden agenda of agent-client interactions with some interpretations from the perspective of socio-cultural interpretation with empirical data.

In conclusion, the study aims to investigate the dynamics of insurance sales agent-client interactions in transformational rural China, and it is found that in rural areas, the decision of making the purchase of insurance policy can be summarized as the following:

Firstly, there is the emergence of an understanding of the necessity of such a service given the fact of the insufficiency of social security the government offers in such areas as education, medical expenses and pension plans. While at the same time, due to the rising standard of living of local residents, simply put, there is financial feasibility to purchase further services to improve their well-being.

Secondly, in transformational China's rural communities, Guanxi, Renqing, connections are still quite rampant and pervasive in everyday life, from daily life to dealing with others. While currently, insurance sales in rural areas are still mostly conducted through the agents' extensive connections with the local residents, for most of the time, the sales are achieved through the trust of the clients in the agents, which requires almost impeccable credibility and reputation of the agents, that is also why almost all agents who are doing well (having good sales performance) are locally well-respected individuals.

Thirdly, the changing social conditions, or the decentralization of central authority, presupposes a downward responsibilization. Individuals are becoming more and more independent and assume more responsibility, not only greater freedom in earning, making a living, but also more risks taken by themselves, compared with the state allocation of resources. It's unwise and dangerous to impose a simple moral judgment of which is better, 
however, it's a general fact and tendency in China's current transformational rural areas.

Fourthly, the selling efforts of the insurance agents' are almost irresistible. In the investigation, there are certain extreme cases that the agents' constant, inexhaustible and repeated visits and talks make the prospective annoyed and thus the whole situation turned into a mess, which could also be one of the reasons that in current transformational China, many people have certain bias or prejudice against insurance sales agents.

Last but not the least, given the fact that people's living standard is getting higher and higher, more and more wealth accumulated through various means, many people just don't have the necessary knowledge or expertise on how to manage their wealth, thus they have to resort to someone who seems to have the relative knowledge and expertise, which thus offers some room for the insurance agents to take advantage of the confusion and make the sales. Moreover, the rapid improvement in life makes the local residents be eager to show off, just as an old Chinese saying goes, "If not return home after getting rich, it's just like parade with beautiful dresses at night". The idea of "face" in the Chinese people's minds is deeply ingrained, therefore, the work of agents can, to some extent, satisfy the need and fill this vanity.

\section{References}

Askehave, I., \& Swales, J. M. (2001). Genre Identification and Communicative Purpose: A Problem and A Possible Solution. Applied Linguistics, 22, 195-212. http://dx.doi.org/10.1093/applin/22.2.195

Baker, T., \& Simon, J. (2013). Embracing Risk: The Changing Culture of Insurance and Responsibility. Chicago Scholarship Online: March 2013.

Bargiela-Chiappini, F. (2009). The Handbook of Business Discourse. Edinbourgh: Edinburgh University Press.

Beck, U. (1992). Risk Society: Towards a New Modernity. London: Sage.

Bhatia, V. K. (2005). Generic Patterns in Promotional Discourse. In H. Halmari \& T. Virtannen (Eds.), Persuasion across Genres: A Linguistic Approach. Amersterdam/Philadelphia: John Benjamins Publishing Company. http://dx.doi.org/10.1075/pbns.130.13bha

Boden, D. (1983). Talk International: An Examination of Turn-taking in Seven Indo-European Languages. Paper presented at the American Sociological Association Meetings, Detroit.

Brown, P., \& Levinson, S. C. (1987). Politeness: Some Universals in Language Usage. Cambridge: Cambridge University Press.

Cameron, D., McAlinden, F., \& O' Leary, K. (1988). Lakoff in Context: The Social and Linguistic Functions of Tag Questions. In J. Coates \& D. Cameron (Eds.), Women in Their Speech Communities.

Cao, H. X. (2009). A Discussion on China's Insurance Marketing System Reform, Management Observer.

Cao, J. Q., \& Chen, Z. Y. (1997). Walking out of the Ideal Castle: Study on the Chinese "Danwei” Phenomenon. Shenzhen: Haitian Press.

Cheng, W. (2003). Intercultural Conversation. Amsterdam and Philadelphia: John Benjamins. http://dx.doi.org/10.1075/pbns.118

Chua, R. Y. J., Morris, M. W., \& Ingram, P. (2009). Guanxi VS Networking: Distinctive Configurations of Affect- and Cognition-based Trust in the Networks of Chinese VS American Managers. Journal of International Business Studies, 40, 490-508. http://dx.doi.org/10.1057/palgrave.jibs. 8400422

Diana, B. (2002). Applying Sociolinguistics. Amsterdam: John Benjamins.

Dijk, V., \& Teun, A. (2006). Discourse and Manipulation, Discourse and Society (pp. 359-383). London: Sage Publications.

Ding, Z. S. (2008). A Study on China's Insurance Market Development. Insurance Studies.

Don, Y. L., \& Philip, L. D. (2005). Trust, and Long-Term Orientation in Chinese Business Markets. Journal of International Marketing, 13(2), 28-56. http://dx.doi.org/10.1509/jimk.13.2.28.64860

Drew, P., \& Heritage, J. (Eds.). (1992). Analyzing Talk at Work. In P. Drew \& J. Heritage (Eds.), Talk at Work: Interaction in Institutional Settings (pp. 1-65). Cambridge: Cambridge University Press.

Duranti, A. (1998). Ethnography of Speaking: Towards Linguistics of the Praxis. In F. J. Newmyer (Ed.), Linguistics: The Cambridge Survey, VI. Language: The Socio-Cultural Context (pp. 210-228). Cambridge: Cambridge University Press.

Eggins, S., \& Slade, D. (1997). Analyzing Casual Conversation. London: Cassell. 
Ericson, R., \& Doyle, A. (2003). Risk and Morality. Toronto: University of Toronto Press.

Ericson, R., \& Doyle, A. (2004a). Uncertain Business: Risk, Insurance and the Limits of Knowledge. Toronto: University of Toronto Press.

Ericson, R., \& Doyle, A. (2004b). Catastrophe Risk, Insurance and Terrorism, Economy and Society, 33, 135-173. http://dx.doi.org/10.1080/03085140410001677102

Ericson, R., \& Doyle, A. (2004c). Criminalization in Private: The Case of Insurance Fraud. In Law Commission of Canada (Ed.), What is A Crime? Defining Criminal Conduct in Contemporary Society (pp. 99-124). Vancouver: University of British Columbia Press.

Fei, X. T. (1999). The Development Path of China's Urban and Rural Areas-The Research Project of My Life. Collections of Fei Xiaotong, 12. Beijing: Qunyan Publishing.

Fei, X. T. (2007). From the Soil: The Foundations of Chinese Society. Nanjing: Jiangsu Literature and Arts Publishing.

Goffman, E. (1967). Interactional Ritual: Essays on Face-to-Face Behavior. New York: Doubleday Anchor.

Guo, Y. (2009). A Brief Survey of China's Insurance, Modern Economy.

Hayashi, M. (2003). Joint Utterance Construction in Japanese Conversation. Amsterdam and Philadelphia: John Benjamins. http://dx.doi.org/10.1075/sidag. 12

Heritage, J. (1984). A Change-of-state Token and Aspects of Its Sequential Placement. In J. M. Atkinson \& J. Heritage (Eds.), Structure of Social Action: Studies in Conversation Analysis (pp. 299-345). Cambridge: Cambridge University Press.

Hu, W., \& Wang, H. (2009). The Scientific Development of Insurance Industry from a Sociological Perspective. Insurance Studies.

Huo, Y. S. (2004). Mitigation and Pragmatic Adaptation: A Case of Interviews in Traditional Chinese Medicine. Kunming: Yunnan University Press.

Hutchby, I., \& Wooffitt, R. (1998). Conversation Analysis. Cambridge: Polity Press.

Jefferson, G. (2004). Glossary of Transcript Symbols with an Introduction. In G. Lerner (Ed.), Conversation Analysis: Studies from the First Generation. Amsterdam: John Benjamins. http://dx.doi.org/10.1075/pbns.125.02jef

Kong, C. C. (2001). Marketing of Belief: Inter-textual Construction of Network Marketers Identity. Discourse and Society, 11(4), 473-503. http://dx.doi.org/10.1177/0957926501012004004

Kong, C. C. (2002). Managing the Ambiguous and Conflicting Identities of "Up-line" and "Down-line" in a $\begin{array}{llllll}\text { Network Marketing } & \text { Firm. }\end{array}$ http://dx.doi.org/10.1177/14614456020040010301

Kong, C. C. (2003). "Are You My Friend?”: Negotiating Friendship in Conversations between Network Marketers and Their Prospects. Language in Society, 32, 487-522. http://dx.doi.org/10.1017/S0047404503324029

Li, G. X. (2008). The Marketing Mechanism of China's Insurance, Economic Forum.

Liang, Y. (2011). Civil Legislative Concept of Particularistic Trust-A Perspective Based on Two Consecutive Studies. Xuehai Press.

Lin, H. D. (2004). Initiating, Sustaining, and Concluding Social Transactions: An Analysis of Role-play Performance in the Oral Proficiency Interview. Journal of Language and Linguistics, 3, 109-137.

Lu, X. Y. (2002). A Research Report on Contemporary China's Social Strata. Beijing: Social and Scientific Literature Publishing.

Luke, K. K. (1990). Utterance Particles in Cantonese Conversation. Amsterdam and Philadelphia: John Benjamins. http://dx.doi.org/10.1075/pbns.9

Luo, J. D., \& Ye, Y. Z. (2007). Trust Game of the Chinese. Beijing: Social and Scientific Literature Publishing.

Malinowski, B. (1923). The Problem of Meaning in Primitive Languages. In K. O. Charles \& A. I. Richards (Eds.), The Meaning of Meaning (pp. 146-152). London: Routledge.

McAra-McWilliam, I., \& Casalegno, F. (2004). Communication Dynamics in Technological Mediated Learning 
Environments. International Journal of Instructional Technology and Distance Learning, 1(11), 15-34.

Montgomery, B. M. (1988). Quality Communication in Personal Relationships. In Duck (Ed.).

Planken, B. (2005). Managing Rapport in Lingua Franca Sales Negotiations: A Comparison of Professional and Aspiring Negotiations. English for Specific Purposes, 24(2005), 381-400. http://dx.doi.org/10.1016/j.esp.2005.02.002

Punch, K. F. (1998). Introduction to Social Research. London: Sage.

Riggs, F. W. (1964). Administration in Developing Countries. Boston: Houghton Mifflin Company.

Roger, D. (1989). Experimental Studies of Dyadic Turn-taking Behavior. In D. Roger \& P. Bull (Eds.), Conversation (pp. 75-95). Philadelphia: Multilingual Matters.

Rogers, L. E., \& Millar, F. E. (1988). Relational Communication. In Duck (Ed.).

Sacks, H. (1974). An Analysis of the Course of a Joke's Telling in Conversation. In R. Bauman \& J. Sherzer (Eds.), Explorations in the Ethnography of Speaking (pp. 337-353). Cambridge: Cambridge University Press.

Schegloff, E. A. (2000a). Overlapping Talk and the Organization of Turn-taking for Conversation. Language and Society, 29(1), 1-63. http://dx.doi.org/10.1017/S0047404500001019

Shegloff, E. A. (2000b). When "Others" Initiate Repair. Applied Linguistics, 21(2), 205-243. http://dx.doi.org/10.1093/applin/21.2.205

Schegloff, E. A. (2001). Accounts of Conduct in Interaction: Interruption, Overlap and Turn-taking. In J. H. Turner (Ed.), Handbook of Sociological Theory (pp. 287-321). New York: Plenum. http://dx.doi.org/10.1007/0-387-36274-6_15

Scollon, R., \& Scollon, S. W. (2001). Intercultural Communication: A Discourse Approach. New Jersey: Blackwell Publishers.

Sheng, Z. (2009). Retrospect on the Chinese Insurance Market Development in 2008, China Insurance.

Shu, J., \& Li, J. (2006). Moral Risks and Commissioning in Insurance-Agent Model. Journal of Chongqing Institute of Technology.

Strange, S. (1996). The Retreat of the State: The Diffusion of Power in the World Economy. Cambridge: Cambridge University Press. http://dx.doi.org/10.1017/CBO9780511559143

Sun, L. P. (2009). The Remaking of Society-Order Reconstruction in Transformational Society. Beijing: Social and Scientific Literature Publishing.

Swales, J. (1991). Genre Analysis—English in Academic and Research Settings. Cambridge: Cambridge University Press.

Swales, J. M. (2004). Research Genres: Explorations and Applications. Cambridge: Cambridge University Press. http://dx.doi.org/10.1017/CBO9781139524827

Swales, J. M., \& Rogers, P. S. (1995). Discourse and the Projection of Corporate Culture: The Mission Statement. Discourse \& Society, 6, 223-242. http://dx.doi.org/10.1177/0957926595006002005

Tanaka, H. (1999). Turn-taking in Japanese Conversation: A Study in Grammar and Interaction. Amsterdam and Philadelphia: John Benjamins.

Tang, M., \& Huhe, N. (2014). The Variant Effect of Decentralization on Trust in National and Local Governments in Asia. Political Studies. http://dx.doi.org/10.1111/1467-9248.12177

Xu, X. (2009). An Exploration of Overseas Academic Studies on Issues of China's Insurance Industry, Shanghai Insurance.

Yang, M. (1994). Gifts, Favors, and Banquets: The Art of Social Relationships in China. NY: Cornell University Press.

Yang, Z. F., \& Peng, S. Q. (2009). The Conceptualization of Chinese Interpersonal Trust-An Interpersonal Relational Perspective. Journal of Sociology Studies.

Yuan, L. (2008). Current Situations and Problems of Insurance Agent System in China. Modern Economy.

Zhai, X. W. (2007). The Operating Mechanism of Bao. Journal of Sociology Studies.

Zhai, X. W. (2009). Guanxi, or Social Capital. Society, 29. 
Zhao, J. G. (2013). A Critique on Chinese Guanxi. Beijing: Xinhua Press.

Zhou, X. H. (2014). Social Mentality in Transforming era and Chinese Experience. Journal of Sociology Study, 4.

Zhu, J. (2009). Prospect of Chinese Insurance Market 2009, China Insurance.

Zimmerman, D. H. (1988). On Conversation: the Conversation Analytic Perspective. Communication Yearbook II (pp. 406-432). Newbury Park: Sage.

\section{Note}

Note 1. Village director: in Chinese Pinyin, Cun Zhuren, means the head of a village.

Village director is the head of a village, who is responsible for administrative matters of the village. Elected by the residents of the village and serves a term for three years. (Source: http://baike.baidu.com/view/234559.htm)

\section{Copyrights}

Copyright for this article is retained by the author(s), with first publication rights granted to the journal.

This is an open-access article distributed under the terms and conditions of the Creative Commons Attribution license (http://creativecommons.org/licenses/by/3.0/). 